\title{
YOGA LANSIA PERSPEKTIF AYURWEDA DI TAMAN JEPUN DENPASAR
}

\author{
Anak Agung Eza Laksmi Dewi ${ }^{1}$, Sang Ayu Made Yuliari ${ }^{2}$, Ida Bagus Wiryanatha ${ }^{3}$ \\ Fakultas Kesehatan Universitas Hindu Indonesia, Denpasar Bali \\ ${ }^{1}$ ezalaksmi10@gmail.com*; \\ * Corresponding author
}

\begin{abstract}
Populasi penduduk berusia lanjut (lansia) yang meningkat seiring dengan bertambahnya usia dapat mempengaruhi kualitas hidup lansia, pada sisi lain dalam Ayurweda disebutkan bahwa membuat semua orang sehat dan berumur panjang. Dalam meningkatkan keseimbangan, kekuatan otot, dan kebugaran tubuh lansia memilih mengikuti latihan yoga, Taman Jepun Denpasar merupakan salah satu tempat strategis yang digunakan untuk berlatih yoga oleh para lansia. Pada penelitian ini dirumuskan masalah mengapa lansia beryoga, jenis dan tata cara latihan yoga apa saja yang dilakukan oleh lansia serta manfaat yang dirasakan lansia selama mengikuti latihan yoga. Jenis penelitian adalah kualitatif yang didapatkan melalui teknik pengumpulan data dengan metode purposive sampling, data diperoleh dengan cara melakukan wawancara kepada 15 (lima belas) orang responden lansia. Pembahasan dilakukan dengan pendekatan ayurweda menggunakan teori yoga dan teori kesehatan. Berdasarkan hasil penelitian disimpulkan bahwa Yoga Lansia Perspektif Ayurweda Di Taman Jepun Denpasar sangat diperlukan oleh para lansia untuk mengatasi keluhan yang dialami, menjaga keseimbangan tubuh, berolahraga sesuai dengan usia, merasakan ada rasa kekeluargaan di dalam komunitas Bali Happy. Adapun 3 (tiga) jenis latihan yoga yaitu Yoga Tertawa, Yoga Suryanamaskara, dan Yoga Jagadhita. Latihan yoga dirasakan bermanfaat untuk meningkatkan keseimbangan tubuh dengan tetap menjaga pola makanan, minuman (ahara), merasakan ketenangan, tubuh lebih sehat, rutin berolahraga (vihara), memperbaiki kualitas tidur menjadi lebih baik (nidra).
\end{abstract}

Kata Kunci : Yoga, Lansia, perspektif ayurweda

The population of the elderly (elderly) which increases with age can affect the quality of life of the elderly, on the other hand in Ayurveda it is mentioned that making everyone healthy and long-lived. In improve the balance, muscle strength, and body fitness of the elderly choosing to follow yoga practice, Taman Jepun Denpasar is one of the strategic places used to practice yoga by the elderly. In this study the problem was formulated why the elderly yoga, the types and procedures of yoga practice what is done by the elderly and the benefits felt by the elderly during yoga practice. This type of research is qualitative obtained through data collection techniques with a purposive sampling method, data obtained by conducting interviews with 15 (fifteen) elderly respondents. The discussion was carried out using the ayurveda approach using yoga theory and health theory. Based on the results of the study it was concluded that the Elderly Perspective Yoga of Ayurveda in Taman Jepun Denpasar is needed by the elderly to overcome complaints experienced, maintain body balance, exercise according to age, feel a sense of family within the Bali Happy community. The 3 (three) types of yoga exercises are Laughing Yoga, Suryanamaskara Yoga, and Jagadhita Yoga. Yoga practice is felt to be beneficial to improve body balance while maintaining food patterns, drinks (ahara), feeling calm, a healthier body, regular exercise (vihara), improve sleep quality for the better (nidra).

Keywords: Yoga, Elderly, Ayurveda Perspective 


\section{Pendahuluan}

Populasi penduduk berusia lanjut (lansia) meningkat begitu cepat. Tahun 2020, jumlah lansia diprediksi sudah menyamai jumlah anak dibawah usia 5 tahun (balita). Lansia berkaitan erat dengan berbagai penurunan status kesehatan terutama status kesehatan fisik. Menurunnya status lansia ini berlawanan dengan tujuan hidup menurut Ayurweda, yaitu membuat semua orang sehat dan berumur panjang yang disebut dengan "Dirghajivitam Sukhayu". Hal ini diperkuat oleh (Miller, 2012:65) yang berpendapat bahwa bertambahnya usia bisa diiringi dengan timbulnya berbagai penyakit, penurunan fungsi tubuh, keseimbangan tubuh dan risiko jatuh. Menurunnya status kesehatan lansia ini berlawanan dengan keinginan para lansia agar tetap sehat, mandiri dan dapat beraktivitas seperti biasa misalnya mandi, berpakaian, berpindah secara mandiri.

World Health Organization (WHO) mendefinisikan makna sehat sebagai keadaan sejahtera secara fisik, mental dan sosial yang merupakan satu kesatuan, bukan hanya terbebas dari penyakit maupun kecacatan. Definisi sehat yang lain menurut UU Kesehatan No.36 tahun 2009 adalah keadaan sehat baik secara fisik, mental, spiritual maupun sosial yang memungkinkan setiap orang untuk bisa hidup lebih produktif secara sosial dan ekonomis (Endang Wahyati Yustina, 2014:-). Kebutuhan yang semakin kompleks menggiring manusia untuk semakin memfokuskan diri dalam kesehariannya bekerja sehingga perhatian manusia untuk menjaga kesehatan menjadi berkurang. Menurut (Nala, 2001:72) kualitas kesehatan yang baik sangat tergantung dari 3 hal pokok yaitu pola makan, pola istirahat, dan pola aktivitas yang baik di jabarkan dalam ajaran Triupasthamba yaitu Ahara adalah mengkonsumsi makanan yang bergizi seimbang, Vihara adalah berperilaku sehat seperti olahraga teratur, dan Nidra adalah pola istirahat baik serta tidur yang cukup. Pengetahuan tentang pola makan, pola aktivitas dan pola istirahat yang sehat banyak diulas dalam Ilmu Kesehatan Ayurweda.

Ilmu tersebut diperkuat oleh pendapat dari (Kinasih, 2010:18) bahwa aktivitas bekerja yang padat menjadi penghambat untuk seseorang berperilaku sehat seperti olahraga teratur, konsumsi makanan yang bergizi seimbang. Manusia pada dasarnya memiliki motivasi utama untuk meningkatkan kualitas hidupnya dan individu memiliki kemauan yang aktif ke arah kesehatan, impuls ke arah pertumbuhan atau ke arah aktualisasi potensi - potensi manusia. Proses lanjut usia merupakan proses alamiah, yang berarti seseorang telah melalui empat tahap kehidupan yaitu anak, remaja, dewasa, tua. Empat tahap ini berbeda, baik secara biologis, maupun psikologis yang terjadi pada tahap tua adalah depresi. Depresi adalah perasaan sedih, ketidakberdayaan, dan pesimis, yang berhubungan dengan suatu penderitaan. Depresi dapat berupa serangan yang ditujukan kepada diri sendiri atau perasaan marah yang dalam. Fenomena ini jelas mendatangkan sejumlah konsekuensi, antara lain timbulnya masalah fisik, mental, sosial, serta kebutuhan pelayanan kesehatan (Nugroho, 2006:-).

Untuk meningkatkan keseimbangan dapat dilakukan dengan olahraga fisik sesuai dengan Asanas - asanas Yoga. Yoga adalah latihan tentang disiplin tubuh, pikiran dan jiwa. Yoga dapat diakukan oleh orang disabilitas bahkan oleh lansia. Yoga efektif mengurangi gangguan yang berhubungan dengan lansia. Gerakan Yoga dapat meningkatkan keseimbangan, fleksibilitas, serta kekuatan otot. Dengan gerakan asanas - asanas yoga yang dapat dilakukan oleh lansia, diantaranya meditasi, pranayama, asanas, tertawa, sehingga membuat lansia merasakan nyaman ketika melakukan gerakan yoga secara teratur (Yagli, 2012:-).

Di Kota Denpasar terdapat komunitas Bali Happy yang terletak di Taman Jepun jalan Hayam Wuruk Denpasar, Bali. Dengan kondisi tempat yang sangat strategis, bersih, dan indah yang di penuhi dengan tanaman jepun (Frangipani) membuat masyarakat melirik untuk mengikuti kegiatan latihan yoga bersama dengan komunitas Bali Happy. Salah satu bentuk latihan yoga yang dilakukan di Taman Jepun Denpasar dapat diterapkan dan diikuti oleh lansia khususnya, karena gerakan asanas - asanas yoga yang tidak begitu sulit bisa dilakukan beberapa lansia. Bentuk latihan yoga tersebut bisa diterapkan oleh para pemula khususnya lansia untuk mengobati keluhan pada tubuh. Masyarakat yang tergabung dalam komunitas Bali Happy ini melaksanakan latihan secara rutin setiap hari senin dan kamis mulai pukul 17.30 hingga 18.30 Wita di Taman Jepun jalan Hayam Wuruk Denpasar, Bali.

Maka dari itu kebanyakan lansia lebih memilih untuk mengikuti latihan yoga, karena yoga lebih fleksibel dibandingkan dengan senam aerobik dan peragaan bahasa tubuh (body language). Pada umumnya senam aerobik dan body language memiliki gerakan yang relatif cepat dan sulit, biasanya diikuti oleh para remaja dan ibu - ibu usia muda. Dalam prakteknya senam aerobik dan body language ini kurang diminati oleh golongan umur lansia. 


\section{Metode Penelitian}

Penelitian ini difokuskan pada latihan yoga yang diminati oleh lansia khususnya untuk kesehatan jasmani dan rohani di Taman Jepun Denpasar. Pendekatan yang dipergunakan dalam penelitian ini adalah pendekatan ayurweda, dalam Kitab Ayurweda terdiri dari delapan cara pengobatan disebut dengan Astangga Ayurweda yang mengulas tentang psikologi seseorang serta mendorong para lansia sehat dengan latihan yoga lansia di Taman Jepun Denpasar. Berdasarkan landasan tersebut, penelitian ini berusaha mengungkapkan yoga adalah suatu proses penyatuan dari tubuh (body), pikiran (mind), dan jiwa (soul), penyatuan fisik mental dan spiritual untuk mencapai sistem kesehatan menyeluruh (holistik) serta melakukan latihan yoga asanas, meditasi, pranayama melalui pengumpulan data dari latar alami sebagai sumber langsung (Sengupta. P, 2017:58).

Data dalam penelitian ini terdiri atas data kualitatif, terdiri dari data primer dan data sekunder. Peneliti menggunakan data ini untuk mendapatkan informasi langsung tentang Yoga Lansia Perspektif Ayurweda di Taman Jepun Denpasar. Sedangkan data sekunder bersumber dari buku serta jurnal yang memiliki kaitan dengan penelitian. Data yang diambil dengan teknik purposive sampling dan diperoleh dengan metode kepustakaan, observasi, wawancara, dan dokumentasi penelitian. Data yang didapat kemudian di analisis dengan menggunakan metode reduksi data, penyajian data, verifikasi data, serta pengecekan keabsahan data dalam penelitian.

\section{Hasil Penelitian}

Adapun hasil penelitian antara lain kebanyakan dari masyarakat khususnya para lansia peserta Yoga Lansia Persepektif Ayurweda Di Taman Jepun Denpasar mengetahui informasi mengenai komunitas Bali Happy dari teman teman, keluarga, sosial media, media masa, dan mencoba mengikuti latihan yoga bersama dalam komunitas Bali Happy di Taman Jepun Denpasar untuk menjaga keseimbangan, kebugaran tubuh, serta mengatasi keluhan yang dialami oleh para lansia khususnya. Terdapat 3 (tiga) jenis latihan yoga antara lain Yoga Tertawa, Yoga Suryanamaskara, dan Yoga Jagadhita. Dengan beberapa tata cara latihan yoga meliputi tahapan - tahapan sebagai berikut, salam pembuka, latihan pranayama, gerak pemanasan, Yoga Tertawa, Yoga Suryanamaskara dari 12 (dua belas) gerakan diwakili oleh 5 (lima) gerakan yang dipilih oleh instruktur yoga agar mudah untuk diikuti oleh para lansia, Yoga Jagadhita, Meditasi, dan doa penutup.

Tabel 1.1: Instruktur, Alasan Mengajar Yoga

\begin{tabular}{|c|c|c|}
\hline No & Nama & Alasan Mengajar \\
\hline 1 & $\begin{array}{l}\text { Anak Agung } \\
\text { Gede Sukarena, } \\
63 \text { thn (L) }\end{array}$ & $\begin{array}{l}\text { SebeYurgnya beliau } \\
\text { pernah mengalami sakit } \\
\text { psikosomatik, setelah } \\
\text { rutin mengikuti latihan } \\
\text { yoga di Ambar Ashram } \\
\text { beliau bisa sembuh dari } \\
\text { sakit tersebut, dan beliau } \\
\text { berkomitmen ingin } \\
\text { mengajar di Taman } \\
\text { Jepun Denpasar } \\
\text { kemudian mengajak } \\
\text { peserta yoga untuk } \\
\text { menjadi hidup yang } \\
\text { lebih baik dan sehat. }\end{array}$ \\
\hline
\end{tabular}

Sumber: Penelitian 2020

Tabel 1.2: Responden, Umur, dan Keluhannya

\begin{tabular}{|c|c|c|}
\hline No & Nama & $\begin{array}{c}\text { Keluhan Sebelum } \\
\text { Latihan Yoga }\end{array}$ \\
\hline 1 & $\begin{array}{c}\text { Ketut Apung, } \\
69 \text { thn (L) }\end{array}$ & $\begin{array}{c}\text { Sakit jantung, sakit kaki, } \\
\text { penurunan metabolisme } \\
\text { tubuh }\end{array}$ \\
\hline 2 & $\begin{array}{c}\text { Nyoman } \\
\text { Rudana, } \\
\text { Wayan } \\
\text { Losmen, }\end{array}$ & Sakit jantung \\
\hline 4 & $\begin{array}{c}\text { Gusti Ayu } \\
\text { Suryani, }\end{array}$ & Sakit jantung \\
\hline 5 & $\begin{array}{c}\text { Ida Ayu } \\
\text { Agung }\end{array}$ & $\begin{array}{c}\text { Cemas dan } \\
\text { reumatik }\end{array}$ \\
\hline
\end{tabular}




\begin{tabular}{|c|c|c|}
\hline 6 & $\begin{array}{l}\text { Ni Nengah } \\
\text { Puspawati, }\end{array}$ & Cemas berlebihan, Stress \\
\hline 7 & $\begin{array}{l}\text { Mtulya, } \\
56 \text { thn (P) }\end{array}$ & $\begin{array}{l}\text { Sakit kaki yang tidak } \\
\text { dapat ditekuk }\end{array}$ \\
\hline 8 & $\begin{array}{l}\text { Nyoman } \\
\text { Nendri, }\end{array}$ & Sakit pada kaki kiri \\
\hline 9 & $\begin{array}{c}\text { Nyoman Rana, } \\
65 \text { thn (L) }\end{array}$ & Sakit pada bagian kaki \\
\hline 10 & $\begin{array}{l}\text { I Nyoman } \\
\text { Kariasa, } \\
63 \text { thn (L) }\end{array}$ & $\begin{array}{c}\text { Badan merasa berat dan } \\
\text { sakit }\end{array}$ \\
\hline 11 & $\begin{array}{l}\text { Susanti Yulia, } \\
56 \text { thn }(\mathrm{P})\end{array}$ & $\begin{array}{c}\text { Badan merasa sakit dan } \\
\text { berat }\end{array}$ \\
\hline 12 & $\begin{array}{l}\text { Ida Bagus } \\
\text { Purwaka, } \\
69 \text { thn (L) }\end{array}$ & $\begin{array}{l}\text { Badan terasa berat dan } \\
\text { merasa sakit }\end{array}$ \\
\hline 13 & $\begin{array}{l}\text { Ni Wayan } \\
\text { Supiati, } \\
61 \text { thn }(\mathrm{P})\end{array}$ & $\begin{array}{l}\text { Tidak ada keluhan, } \\
\text { menjaga kesehatan tubuh }\end{array}$ \\
\hline 14 & $\begin{array}{c}\text { Anak Agung } \\
\text { Istri } \\
\text { Kusuma } \\
\text { Wardani, } \\
55 \text { thn }(\mathrm{P}) \\
\end{array}$ & $\begin{array}{l}\text { Tidak ada keluhan, } \\
\text { menjaga kesehatan tubuh }\end{array}$ \\
\hline 15 & $\begin{array}{l}\text { Wayan, } \\
70 \text { thn }(\mathrm{L})\end{array}$ & $\begin{array}{l}\text { Tidak ada keluhan, } \\
\text { menjaga kesehatan tubuh }\end{array}$ \\
\hline
\end{tabular}

Adapun manfaat yang dirasakan dari 15 (lima belas) peserta yoga yaitu dapat mengatasi rasa cemas berlebihan, mengatasi rasa sakit pada tubuh, kualitas tidur menjadi lebih baik, meningkatkan ketenangan dalam diri, merasakan tingkat pendalaman spiritual dan aura menjadi lebih baik, terjaganya keseimbangan tubuh, dan metabolism tubuh semakin baik.

\section{Pembahasan}

Yoga Lansia Perspektif Ayurweda di Taman Jepun Denpasar merupakan salah satu tempat strategis yang digunakan untuk tempat berlatih yoga oleh para lansia, selain itu para lansia juga ingin mengatasi keluhan yang dialami, menjaga keseimbangan tubuh, dan ingin merasakan ketenangan pikiran serta didukung oleh tempat latihan yang bersih, aman, dan nyaman.
Yoga merupakan sistem kesehatan menyeluruh (holistik). Dalam perspektif ayurweda terdapat 3 (tiga) keseimbangan tubuh yang harus dijaga, disebut dengan Tri dosha atau tiga dosha tersebut antara lain vata (udara), pitta (api), kapha (air) harus dalam keadaan seimbang untuk mencapai sistem kesehatan menyeluruh (holistik), Swasthasya yang artinya mengobati seseorang yang sakit menjadi sehat dan memelihara kesehatan orang yang sehat sehingga selalu dalam keadaan sehat (Singhal, 2007:141). Menurut MahaRsi Patanjali yang mengartikan tentang yoga dalam kitab (Yogasutra, I:2) antara lain: citta vrtti nirodhah, citta adalah "pikiran" yang artinya yaitu mengendalikan gerak- gerik pikiran.

Hasil analisis data diatas mengenai jenis dan tata cara Yoga Lansia Perspektif Ayurweda di Taman Jepun Denpasar didukung oleh pustaka yaitu, teknik pernapasan (pranayama) merupakan penunjang yang sangat penting dalam latihan yoga. Pernapasan dilakukan dengan cara menarik napas (puraka) pada keadaan normal udara masuk ke dalam paru - paru melalui hidung, menahan napas (kumbhaka) memberi kesempatan kepada darah untuk mengambil oksigen dari udara di dalam paru - paru dan melepaskan oksigen ke jaringan tubuh, mengeluarkan napas (recaka) udara keluar dari paru - paru, menunda napas (sunyaka) sudah mengeluarkan napas ada sedikit jeda sebelum menarik napas kembali (Somvir,

2008:15).

Latihan Yoga Surya Namaskara yang memiliki pengertian Sang Surya adalah salah satu kekuatan Tuhan yang ada pada matahari yang memberikan kekuatan dan sinar kesucian pada alam semesta beserta isinya, Namaskara dapat diartikan adalah suatu sikap sembah bhakti seseorang kehadapan Tuhan yang disucikan dalam menyelarasakan hubungan antara manusia dengan Tuhan. Selain itu latihan Yoga Surya Namaskara digunakan untuk menyembuhkan beberapa penyakit yang berhubungan dengan fisiologi manusia, proses penyembuhan tidak bisa dirasakan dalam waktu yang singkat tetapi dirasakan secara bertahap atau perlahan - lahan. Dalam pengajaran MahaRsi Patanjali mempraktekan Astangga Yoga adalah 8 (delapan) tahapan yoga yang saling berhubungan dan terkait satu dengan yang lainnya, 8 (delapan) tahapan tersebut adalah (1) Yama, (2) Nyama, (3) Asana, (4) Pranayama, (5) Prathyahara, (6) Dharana, (7) Dhyana, (8) Samadhi. Sehingga melalui tahapan Astangga Yoga dapat membuat para lansia dalam keadaan sehat jasmani dan rohani yang disebut dengan Swasthasya (Yasa dkk, 2011:25).

Adapun pengertian Yama adalah 5 (lima) pengendalian diri pada tingkat jasmani yang 
harus diatur dan dilakukan. Kelima pengendalian itu adalah: (1) Ahimsa, yaitu tidak melakukan kekerasan kepada mahkluk lain, (2) Satya, yaitu bersikap jujur dan setia pada ucapan juga perbuatan, (3) Asteya, yaitu tidak mencuri atau tidak menginginkan milik orang lain, (4) Brahmacarya, yaitu mengendalikan nafsu asmara, (5) Aparigraha, yaitu hidup sederhana dan tidak serakah. Sedangkan pengertian dari Nyama adalah 5 (lima) pengendalian diri tingkat rohani yang harus diarahkan. Kelima hal itu adalah: (1) Sauca, yaitu kebersihan lahir batin, (2) Santosa, berusaha menjaga kedamaian, ketenangan, serta kestabilan emosi, (3) Tapa, yaitu berusaha berpegang teguh pada ajaran dharma, (4) Swadhyaya, yaitu berusaha tekun serta belajar mandiri, (5) Iswarapranidhana, pengabdian kepada Tuhan Yang Maha Esa (Yuda, 2015:6).

Tabel 1.3: Langkah Tata Cara Latihan Yoga di Taman Jepun Denpasar

\begin{tabular}{|c|c|c|}
\hline No & Nama Asana & $\begin{array}{c}\text { Manfaat asana } \\
\text { untuk lansia }\end{array}$ \\
\hline 1 & Salam Pembuka & $\begin{array}{l}\text { Membangkitkan } \\
\text { semangat peserta, } \\
\text { meningkatkan } \\
\text { rasa kekeluargaan } \\
\text { diantara peserta }\end{array}$ \\
\hline 2 & Pranayama & $\begin{array}{l}\text { Melatih sistem } \\
\text { pernapasan, } \\
\text { melancarkan } \\
\text { sistem pernapasan }\end{array}$ \\
\hline 3 & Pemanasan & $\begin{array}{l}\text { Meregangkan otot } \\
\text { - otot, } \\
\text { meningkatkan } \\
\text { suhu badan, } \\
\text { mengurangi risiko } \\
\text { cedera }\end{array}$ \\
\hline 4 & Yoga Tertawa & $\begin{array}{l}\text { Mengeluarkan } \\
\text { hormon endorphin, } \\
\text { meningkatkan } \\
\text { energi, } \\
\text { menghilangkan rasa } \\
\text { cemas dan stress }\end{array}$ \\
\hline 5 & $\begin{array}{c}\text { Yoga } \\
\text { Suryanamaskara }\end{array}$ & $\begin{array}{l}\text { Membantu } \\
\text { menyeimbangkan } \\
\text { tubuh, } \\
\text { membangkitkan } \\
\text { energi, } \\
\text { meningkatkan } \\
\text { kekuatan tubuh, }\end{array}$ \\
\hline
\end{tabular}

\begin{tabular}{|c|c|l|}
\hline 6 & Yoga Jagadhita & $\begin{array}{l}\text { Merilekskan } \\
\text { pikiran dan tubuh, } \\
\text { meringankan, } \\
\text { menghilangkan } \\
\text { pegal tubuh }\end{array}$ \\
\hline 7 & Meditasi & $\begin{array}{l}\text { Menstabilkan } \\
\text { pikiran, } \\
\text { mengendalikan } \\
\text { gerak - gerik } \\
\text { pikiran }\end{array}$ \\
\hline
\end{tabular}

Sumber: Penelitian 2020

Berdasarkan analisis data diketahui bahwa dari 15 (lima belas) responden peserta yoga lansia di Taman Jepun Denpasar menyatakan bahwa latihan yoga dapat mengatasi keluhan sakit yang dialami, meningkatkan ketenangan dalam diri, tingkat pendalaman spiritual dan aura menjadi lebih baik, mengatasi rasa cemas yang berlebihan, terjaganya keseimbangan tubuh, meningkatkan energi dalam tubuh, lebih sehat dan kuat dalam melakukan aktivitas sehari - hari, metabolisme tubuh semakin baik, kualitas tidur menjadi lebih baik. Adapun upaya pelayanan kesehatan yang dilakukan untuk menjaga kesehatan tubuh secara lengkap meliputi, pelayanan promotif (promosi), preventif (pencegahan), kuratif (pengobatan), rehabilitatif (pemulihan). Dalam Perspektif Ayurweda terdapat 4 (empat) pilar kesehatan antara lain Chikitsitasya Nirdishtam Pratyekam Tat Cha Chaturgunam (Ashtanga Hridaya Sutra Sthanam 1/27-29), yang menyatakan bahwa di dalam 4 (empat) pilar kesehatan tersebut mencakup adanya 1). Dokter (Bhisak) yaitu untuk mengobati seseorang yang memiliki keluhan sakit, 2). Obat - obatan (Drvya) yaitu pemberian obat untuk mengatasi keluhan yang dialami oleh seseorang, 3). Asisten atau perawat (Upasthatha) yaitu untuk merawat seseorang yang memiliki keluhan sakit, dan 4). Pasien (Rogi) yaitu seseorang yang memiliki keluhan sakit dan harus mendapatkan perawatan dengan baik. Latihan yoga secara teratur dapat meningkatkan rasa percaya diri, pola berpikir yang lebih positif, fokus terhadap suatu masalah, membuat tubuh menjadi lebih sehat dan kuat, keseimbangan tubuh tetap terjaga. Teori kesehatan dalam ayurweda terdapat 3 (tiga) konsep sehat yang disebut Tri Upastamba yaitu menjaga keseimbangan tubuh yang harus tetap dalam keadaan seimbang. Ketiga unsur dalam Tri Upastamba yaitu: (1). Ahara (makanan dan minuman), (2). Vihara (berolahraga), (3). Nidra (istirahat / tidur yang cukup). 


\section{Simpulan dan Saran}

Berdasarkan hasil penelitian dan pembahasan tentang Yoga Lansia Perspektif Ayurweda Di Taman Jepun Denpasar, maka bisa disimpulkan sebagai berikut: 1). Latihan yoga di Taman Jepun Denpasar mampu menyeimbangkan tubuh dan pikiran, tubuh dilatih dengan beberapa gerak asanas yang sesuai dengan usia lansia, lebih dalam dengan melatih pranayama serta pikiran yang dilatih melalui meditasi, serta tempat latihan yang nyaman menarik hati para lansia untuk mengikuti latihan yoga. 2). Jenis dan tata cara pelaksanaan yoga lansia di Taman Jepun Denpasar yaitu 3 (tiga) jenis yoga yaitu Yoga Tertawa, Yoga Suryanamaskara, dan Yoga Jagadhita adapun tata cara latihan yoga diawali dengan salam pembuka, pranayama, pemanasan, latihan Yoga Tertawa, Yoga Suryanamaskara, Yoga Jagadhita, Meditasi dan doa penutup. 3). Manfaat yang dirasakan lansia setelah mengikuti latihan yoga, antara lain: dapat mengatasi keluhan yang dialami, dapat tetap menjaga kebugaran tubuh, kualitas tidur menjadi lebih baik, meningkatkan ketenangan dalam diri, terjaganya keseimbangan tubuh dengan baik, metabolisme tubuh semakin baik, meningkatkan energi sehingga lebih aktif dalam melaksanakan aktivitas sehari - hari, lebih sehat, bahagia, tenang dan damai.

Berdasarkan pembahasan dan simpulan penelitian tentang Yoga Lansia Perspektif Ayurweda Di Taman Jepun Denpasar, maka bisa disarankan sebagai berikut: 1). Disarankan kepada masyarakat yang memiliki lansia bila mengalami keluhan fisik atau psikis untuk memilih terapi yoga pada pusat - pusat pelatihan yoga yang terjamin keamanannya seperti yang ada di Taman Jepun Denpasar. 2). Untuk memperoleh hasil yang maksimal dalam pelatihan yoga, peserta (para lansia) disarankan agar tekun dan rutin berlatih mengikuti tahapan-tahapan latihan yang telah dipersiapkan sehingga harapan berlatih yoga bisa segera dirasakan. 3). Mengingat keterbatasan waktu dan kemampuan peneliti, selanjutnya disarankan ada pihak yang dapat mengadakan penelitian serupa sehingga hasil penelitian tentang Yoga Lansia Perspektif Ayurweda menjadi lebih sempurna dengan berpegangan dari hasil penelitian ini.

\section{Daftar Pustaka}

Endang Wahyati Yustina, 2014. Hak Atas Kesehatan Dalam Program Jaminan Kesehatan Nasional Dan Corporate Social Responsibility (CSR) Endang Wahyati Yustina

1.
Kinasih, A.S., 2010. Pengaruh Latihan Yoga Terhadap.

Pengaruh Latihan Yoga Terhadap
Peningkatan
Kualitas Hidup, 18 (1), pp.1-12.

Miller, C.A. (2012). Nursing for wellness in older adult:

Theory and Practice ( $6^{\text {th }} E d$.). Philadelphia: Lippincott Williams \& Wilkins.

Nala, I Gusti Ngurah, 2001. Ayurveda Ilmu Kedokteran Hindu. Jilid 1. Cetakan 1 Denpasar: PT. Upada Sastra.

Nugroho, W. 2006. Keperawatan Gerontik dan Geriatrik, Edisi Dua. Jakarta: EGC.

Singhal, S.N Tripathi, K.R Sharma. 2007. Dalam Madhava-Nidana Jahavar Nagar: Chaukhamba Sanskrit Pratishthan.

Somvir. 2008. Hidup Sehat dan Bahagia dengan Yoga. Yoga for Health a Voice of Bali edisi 4, April 2008 hlm 4. Bali: Penerbit Yayasan Bali-India Fondation.

WHO. (2013). World health statistics 2013. Geneva: WHO press.

Yasa, S., Wirawan, I.G. B., Sukarma, I W., Yamadiputra I W. 2011. Yoga Marga Rahayu. Denpasar: Lembaga Penelitian Universitas Hindu Indonesia.

Yuda, A.A. G. R. 2015. Sehat Bersama Yoga Seger Oger.

Badung: Serat Ismaya. 